\title{
Microwave-Hydrothermal Synthesis of Ferric Oxide Doped with Cobalt
}

\author{
Eman Alzahrani, Abeer Sharfalddin, Mohamad Alamodi \\ Chemistry Department, Faculty of Science, Taif University, Taif, Kingdom of Saudi Arabia \\ Email:em-s-z@hotmail.com, sharfalddin.aa@hotmail.com, dr alamoudi@yahoo.com
}

Received 31 March 2015; accepted 5 May 2015; published 8 May 2015

Copyright (C) 2015 by authors and Scientific Research Publishing Inc.

This work is licensed under the Creative Commons Attribution International License (CC BY).

http://creativecommons.org/licenses/by/4.0/

(c) (i) Open Access

\begin{abstract}
Ferric oxides have drawn significant interest due to their unique properties, relatively low cost, and due to their potential applications in different fields. In this work, cobalt (Co) doped iron oxide $\left(\mathrm{Fe}_{2} \mathrm{O}_{3}\right)$ powders, with crystalline size $36.97 \mathrm{~nm}$ were successfully prepared using a microwave-hydrothermal process for the first time and characterised using different techniques. The morphology of the samples was characterised by scanning electron microscopy (SEM), transmission electron microscopy (TEM), energy dispersive analysis of X-ray spectroscopy (EDAX), Fourier transform infrared (FT-IR) spectroscopy and ultraviolet-visible (UV-Vis) spectroscopy. The images show monodispersed particles with a sharp-edged square morphology. It was found that the average size was about $33.3 \mathrm{~nm}$ for $\mathrm{Fe}_{2} \mathrm{O}_{3}$ and $36.97 \mathrm{~nm}$ for $\mathrm{Co}-\mathrm{Fe}_{2} \mathrm{O}_{3}$. The Co atomic percentage dopants were approximately $\mathbf{5 . 7 3 \%}$. The nanosized synthesised materials in this study may find an application in the areas of removal of toxic metal and dyes research.
\end{abstract}

\section{Keywords}

Nanostructures, Ferric Oxide, Doping, Cobalt, Characterisation

\section{Introduction}

Iron is found in nature in different chemical compounds. Normally, iron has eight electrons on its valence shield, and because of oxygen's electronegativity it can form bivalent and trivalent combinations. These have many applications in different fields such as drug delivery systems [1], cancer treatment [2], magnetic resonance imaging [3], rechargeable lithium batteries, catalysis gas sensors and biosensors [4].

Iron oxides nanocrystals have attracted increasing attention for their outstanding new properties such as their biocompatibility, catalytic activity and low toxicity. In addition, they can be easily separated and removed from 
a solution by simply using an external magnet. There are three different forms of Iron oxide; mainly $\mathrm{FeO}, \mathrm{Fe}_{2} \mathrm{O}_{3}$ and $\mathrm{Fe}_{3} \mathrm{O}_{4}$. $\mathrm{Fe}_{2} \mathrm{O}_{3}$ is the most common oxide of iron and it has four crystallographic phases; namely $\alpha-\mathrm{Fe}_{2} \mathrm{O}_{3}$ (hematite), $\beta-\mathrm{Fe}_{2} \mathrm{O}_{3}, \gamma-\mathrm{Fe}_{2} \mathrm{O}_{3}$ (maghemite) and $\varepsilon-\mathrm{Fe}_{2} \mathrm{O}_{3}$ [5] [6].

Much effort has been devoted to preparing nanoparticles and many methods have been reported for fabricating metal oxides such as forced hydrolysis [7], combustion [8], anhydrous solvent [9], so-gel [10], wet chemical synthesis [11], microwave-hydrothermal synthesis [12] and spray pyrolysis [13]. Among them, the microwavehydrothermal process for fabrication of nanoparticles is a new technique. It is a combination of hydrothermal and microwave processes. There are many advantages for using this method such as savings in energy and time and the low temperature requirements for the synthesis of anaphase materials.

Doping of transition metal ions into $\mathrm{Fe}_{2} \mathrm{O}_{3}$ can improve the properties of nanocrystalline materials by narrowing the energy-band gap and inhibiting electron-hole recombination [4]. So far there are no reports for using the microwave-hydrothermal method for the preparation of $\mathrm{Co}-\mathrm{Fe}_{2} \mathrm{O}_{3}$ nanoparticles; therefore this technique was used in this study to fabricate Co-doped $\mathrm{Fe}_{2} \mathrm{O}_{3}$ nanopowders. The physical properties of the prepared nanoparticles were then studied.

\section{Experiment}

\subsection{Chemicals and Materials}

Nonahydrate ferric nitrate $\left(\mathrm{Fe}\left(\mathrm{NO}_{3}\right)_{3} \cdot 9 \mathrm{H}_{2} \mathrm{O}\right)$, hexhydrate cobalt nitrate $\left(\mathrm{Co}\left(\mathrm{NO}_{3}\right)_{2} \cdot 6 \mathrm{H}_{2} \mathrm{O}\right)$, and absolute ethanol $\left(\mathrm{C}_{2} \mathrm{H}_{5} \mathrm{OH}\right)$ were purchased from Sigma-Aldrich (Poole, UK). Hexamethylenetetramine (HMT) was purchased from Fisher Scientific (Loughborough, UK) Distilled water was employed for preparing all the solutions.

\subsection{Instruments}

The microwave digestion system was sourced from CEM Corporation (North Carolina, USA), and the centrifuge from Hettich (Kirchlengern, Germany). A Scholar 171 magnetic stirrer plate was sourced from Corning stirrer (Tewksbury, USA). The oven came from F.LLI GALLI Company (Milano, Italy). The transmission electron microscopy (TEM) was from JEOL Ltd. (Welwyn Garden City, UK), and the scanning electron microscope (SEM) and energy dispersive analysis of X-ray spectroscopy (EDAX) equipment were a Cambridge S360 from Cambridge Instruments (Cambridge, UK). The FT-IR spectra were PerkinElmer RX FTIR $\times 2$ with diamond ATR, and DRIFT attachment from PerkinElmer (Buckinghamshire, UK). The UV-Vis analysis was collected by the Shimadzu UV-2550 spectrophotometer double beam (Nakagyo-Japan).

\subsection{Preparation of $\mathrm{Co}-\mathrm{Fe}_{2} \mathrm{O}_{3}$ Nanoparticles}

The nanoparticles were prepared by the microwave-hydrothermal method using a typical procedure described in previous work [14] with some modification: $4.05 \mathrm{~g}$ of $\mathrm{Fe}\left(\mathrm{NO}_{3}\right)_{3} \cdot 9 \mathrm{H}_{2} \mathrm{O}$ and $1.2 \mathrm{~g}$ of hexamethylenetetramine (HMT) were dissolved in $30 \mathrm{~mL}$ of distilled water and ethanol mixture $(1: 1, \mathrm{v} / \mathrm{v})$ and stirred vigorously (1100 rpm) until dissolved. Then, $2.32 \mathrm{~g}$ of $\mathrm{Co}\left(\mathrm{NO}_{3}\right)_{2} \cdot 6 \mathrm{H}_{2} \mathrm{O}$ was added to the mixture with constant stirring. After 30 minutes, the mixture was transferred into a Teflon-lined stainless-steel autoclave that was placed in the microwave at $160^{\circ} \mathrm{C}$ for 90 minutes. The mixture was left to cool down to room temperature. The resulting precipitate was collected by centrifugation for 10 minutes. The $\mathrm{Co}-\mathrm{Fe}_{2} \mathrm{O}_{3}$ nanoparticles were washed with distilled water and ethanol. Finally, the prepared nanoparticles were dried in an oven at $60^{\circ} \mathrm{C}$ for 24 hours. Undoped $\mathrm{Fe}_{2} \mathrm{O}_{3}$ was also prepared using the same procedure without adding $\mathrm{Co}\left(\mathrm{NO}_{3}\right)_{2} \cdot 6 \mathrm{H}_{2} \mathrm{O}$.

\subsection{Characterisation of the Fabricated Materials}

The surface morphology of the prepared nanoparticles was characterised using scanning electron microscopy (SEM), and transmission electron microscopy (TEM). In addition, the compositional analysis was studied using energy dispersive analysis of X-ray spectroscopy (EDAX). The FT-IR spectra were collected in the attenuated total reflectance (ATR) mode in the range of $500-4000 \mathrm{~cm}^{-1}$. For UV-Vis absorption measurements, the powder samples were dispersed in deionised water with a fixed concentration $\left(5 \mathrm{mg} \cdot 4 \mathrm{~mL}^{-1}\right)$ [15]. The nanomolar suspensions were prepared by milling in order to minimise the reflection of light [16]. 


\section{Results and Discussion}

\subsection{Preparation of the $\mathrm{Co}-\mathrm{Fe}_{2} \mathrm{O}_{3}$ Nanoparticles}

Iron oxide nanoparticles $\left(\mathrm{Fe}_{2} \mathrm{O}_{3}\right)$ have attracted intensive attention because they are common in nature, and are consequently eco-friendly and inexpensive [6]. In this study, a microwave-hydrothermal method was utilised to fabricate nanosized materials to decrease energy consumption, decrease preparation time from days to minutes, and simplify procedures.

Due to the competition between electron-hole pair recombination, metal doping is the perfect modification method to prevent recombination and charge carrier trapping. In literature, $\mathrm{Mg}$ is the most studied P-dopant for $\mathrm{Fe}_{2} \mathrm{O}_{3}$, besides $\mathrm{Ca}$ and $\mathrm{Ti}$, which can be used for P-doping $\mathrm{Fe}_{2} \mathrm{O}_{3}$ [17]. In this work, a new doping method using Co will be discussed. Cobalt is one of the transition metal ions and it can result in higher photocatalytic activity compared with undoped $\mathrm{Fe}_{2} \mathrm{O}_{3}$. Moreover, it can improve optical activity by narrowing the energy-band gap and extend absorption to the visible region [18].

In this study, $\mathrm{Fe}\left(\mathrm{NO}_{3}\right)_{3} \cdot 9 \mathrm{H}_{2} \mathrm{O}$ and $\mathrm{Co}\left(\mathrm{NO}_{3}\right)_{2} \cdot 6 \mathrm{H}_{2} \mathrm{O}$ were used as iron and cobalt sources, respectively. Hexamethylenetetramine (HMT) was used as a molecular building block for self-assembled molecular crystals [19] [20]. Figure 1 shows an image of the fabricated $\mathrm{Co}-\mathrm{Fe}_{2} \mathrm{O}_{3}$ powders.

\subsection{Characterisation of the Fabricated Materials}

\subsubsection{SEM Analysis}

SEM analysis was used to study the surface morphology of the prepared nanoparticles. Figure 2 represents the SEM images of $\mathrm{Fe}_{2} \mathrm{O}_{3}$ and $\mathrm{Co}-\mathrm{Fe}_{2} \mathrm{O}_{3}$ nanoparticles in different magnifications. They demonstrate that the grain size is homogeneous, polygonal and agglomerates. By comparing the micrographs, it was found that no significant morphological differences can be viewed. The agglomeration is ascribed to the removal of nanostructure-stabilising ions by washing with water [21]. Moreover, SEM analysis gives only the average grain size of the samples, which simply represents the fact that each grain is formed by aggregation of a number of nanocrystals.

\subsubsection{EDAX Analysis}

Energy dispersive X-spectroscopy (EDAX) was used to identify elements that exist in the prepared nanosised powders. Figure 3 shows the EDAX patterns and compositions of $\mathrm{Fe}_{2} \mathrm{O}_{3}$ and $\mathrm{Co}-\mathrm{Fe}_{2} \mathrm{O}_{3}$. The results confirm that all the elements appear at their corresponding $\mathrm{keV}$ values. It was observed that there was a new peak in Co$\mathrm{Fe}_{2} \mathrm{O}_{3}$, representing Co, Figure 3(b), which confirms doping of iron oxide $\left(\mathrm{Fe}_{2} \mathrm{O}_{3}\right)$ with cobalt. Table 1 shows the atomic percentages of the nanoparticle elements, which were iron, oxygen and cobalt. It was found that the Co atomic dopant percentage was nearly $5.73 \%$.

\subsubsection{TEM Analysis}

The TEM morphologies and microstructures of the prepared $\mathrm{Fe}_{2} \mathrm{O}_{3}$ and $\mathrm{Co}-\mathrm{Fe}_{2} \mathrm{O}_{3}$ powders are shown in Figure 4. Clearly, they were composed of uniformly dispersed particles, which indicates that high disparity and uni-

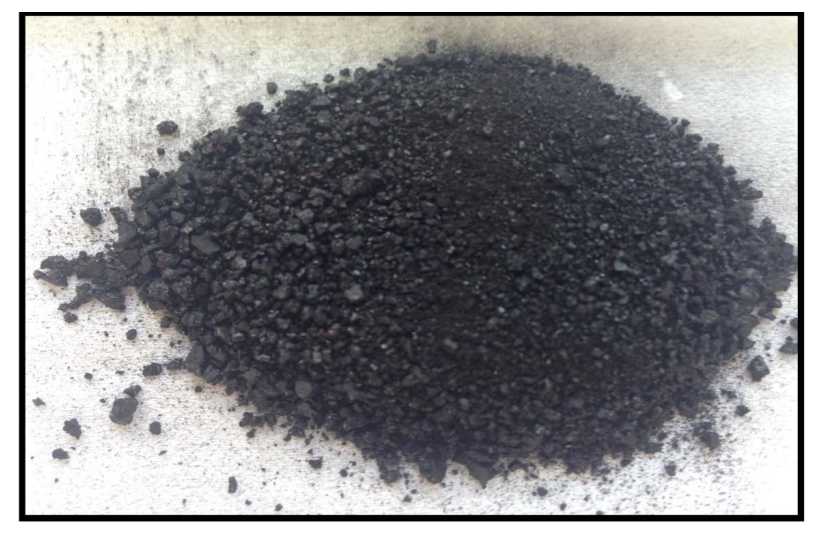

Figure 1. Image of the fabricated $\mathrm{Co}-\mathrm{Fe}_{2} \mathrm{O}_{3}$ powder. 

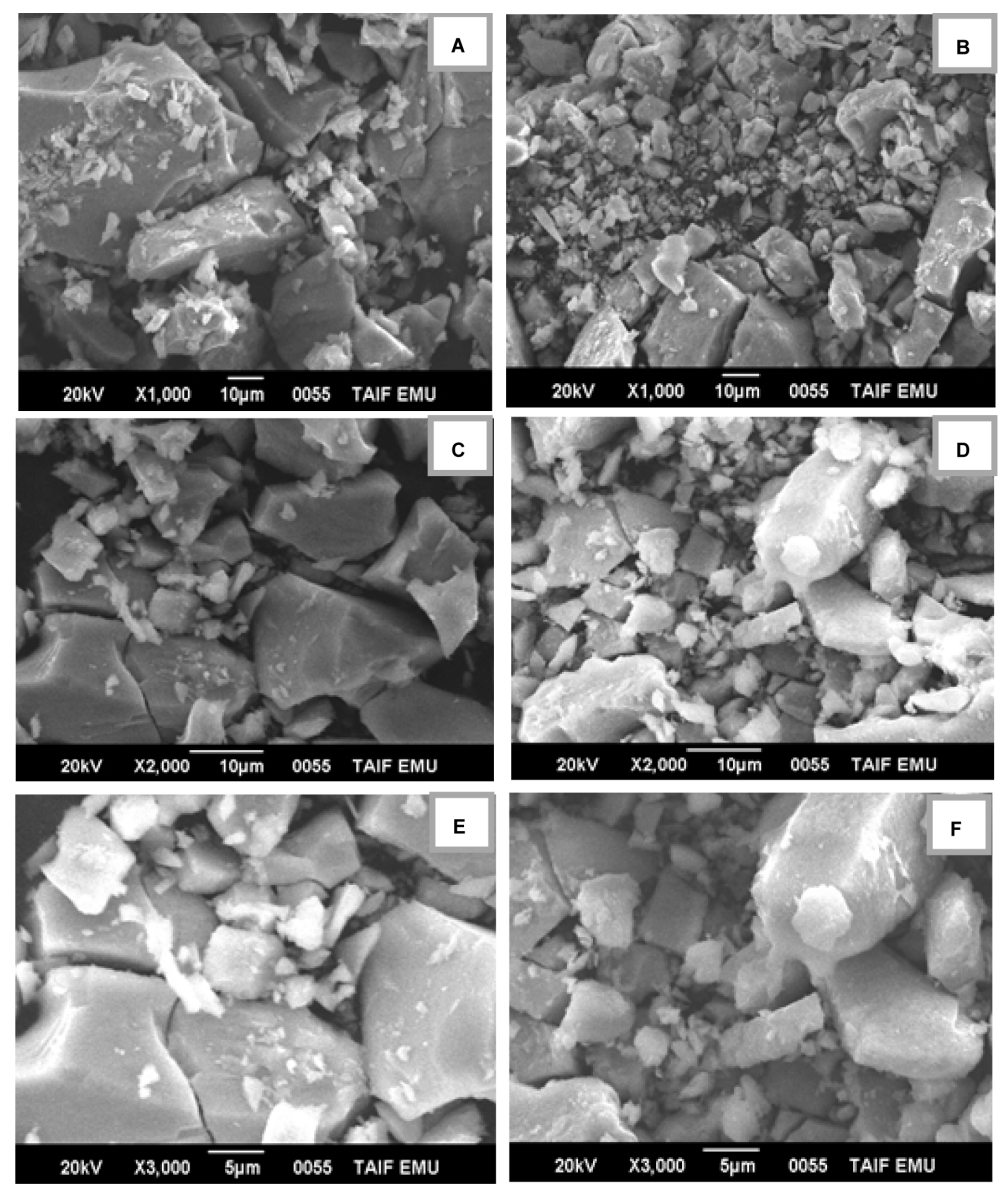

Figure 2. SEM images of (A) (C) and (E) $\mathrm{Fe}_{2} \mathrm{O}_{3}$ and (B, D, and F) $\mathrm{Co}-\mathrm{Fe}_{2} \mathrm{O}_{3}$ using different magnifications.

Table 1. The atomic percentages for $\mathrm{Fe}_{2} \mathrm{O}_{3}$ and $\mathrm{Co}-\mathrm{Fe}_{2} \mathrm{O}_{3}$.

\begin{tabular}{ccccc}
\hline & & Atom \% & Total \\
\cline { 2 - 4 } Sample & Fe \% & $\mathbf{O} \%$ & Co \% & 100.00 \\
$\mathrm{Fe}_{2} \mathrm{O}_{3}$ & 36.02 & 63.98 & 0 & 100.00 \\
\hline
\end{tabular}

formity are achieved using this route. In addition, it was found that $\mathrm{Co}-\mathrm{Fe}_{2} \mathrm{O}_{3}$ maintains the cubic particle structure of the undoped $\mathrm{Fe}_{2} \mathrm{O}_{3}$. The monodispersed particles had a sharp-edged square morphology with an average size range of about $33.3 \mathrm{~nm}$ for $\mathrm{Fe}_{2} \mathrm{O}_{3}$ and $36.97 \mathrm{~nm}$ for $\mathrm{Co}-\mathrm{Fe}_{2} \mathrm{O}_{3}$. It was concluded that the average size of nanoparticles was increased slightly due to Co doping in the $\mathrm{Fe}_{2} \mathrm{O}_{3}$ lattice.

\subsubsection{FT-IR Analysis}

Figure 5 shows the FT-IR spectra of $\mathrm{Fe}_{2} \mathrm{O}_{3}$ and $\mathrm{Co}-\mathrm{Fe}_{2} \mathrm{O}_{3}$. The bands cantered at $3335 \mathrm{~cm}^{-1}$ and $1574 \mathrm{~cm}^{-1}$ are ascribed to the $\mathrm{O}-\mathrm{H}$ bonding stretching and bending vibrational modes, respectively [22]. It suggests the presence of very small amount of free and adsorbed water on the surface of the samples. In addition, a peak at around $563 \mathrm{~cm}^{-1}$ is ascribed to the stretching between iron and oxygen in $\mathrm{Fe}_{2} \mathrm{O}_{3}$. The absorption band located at $523 \mathrm{~cm}^{-1}$ in the $\mathrm{Co}-\mathrm{Fe}_{2} \mathrm{O}_{3}$ nanoparticles samples was attributed to metal dopant-oxygen stretching modes. Similar observations have been documented in literature [23] [24]. The absorption bands around $1030 \mathrm{~cm}^{-1}$ and 1110 $\mathrm{cm}^{-1}$ are caused by the vibration of crystalline Fe-O modes, which are characteristic of $\mathrm{Fe}_{2} \mathrm{O}_{3}$ [25]. On doping, 


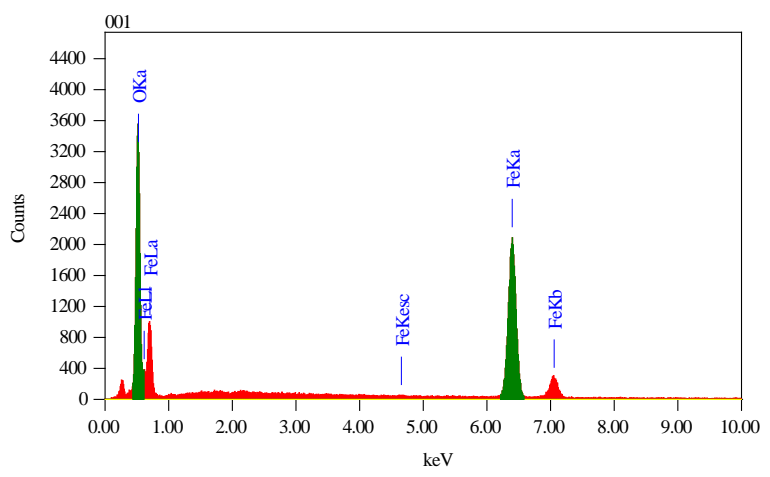

(a)

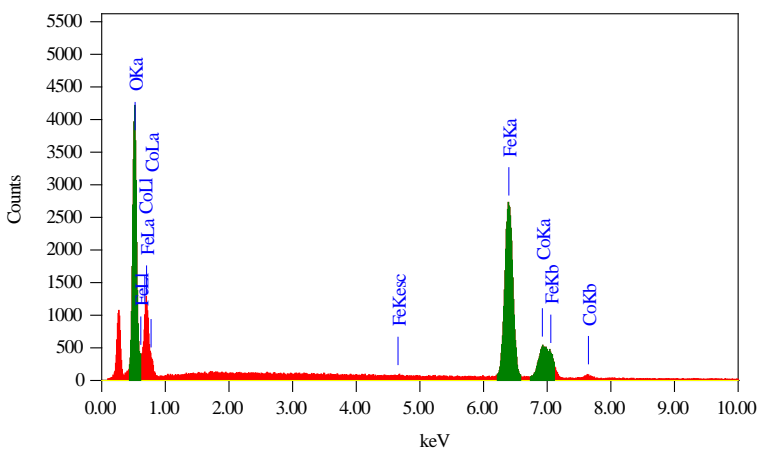

(b)

Figure 3. EDAX spectra of (a) $\mathrm{Fe}_{2} \mathrm{O}_{3}$ and (b) $\mathrm{Co}-\mathrm{Fe}_{2} \mathrm{O}_{3}$.
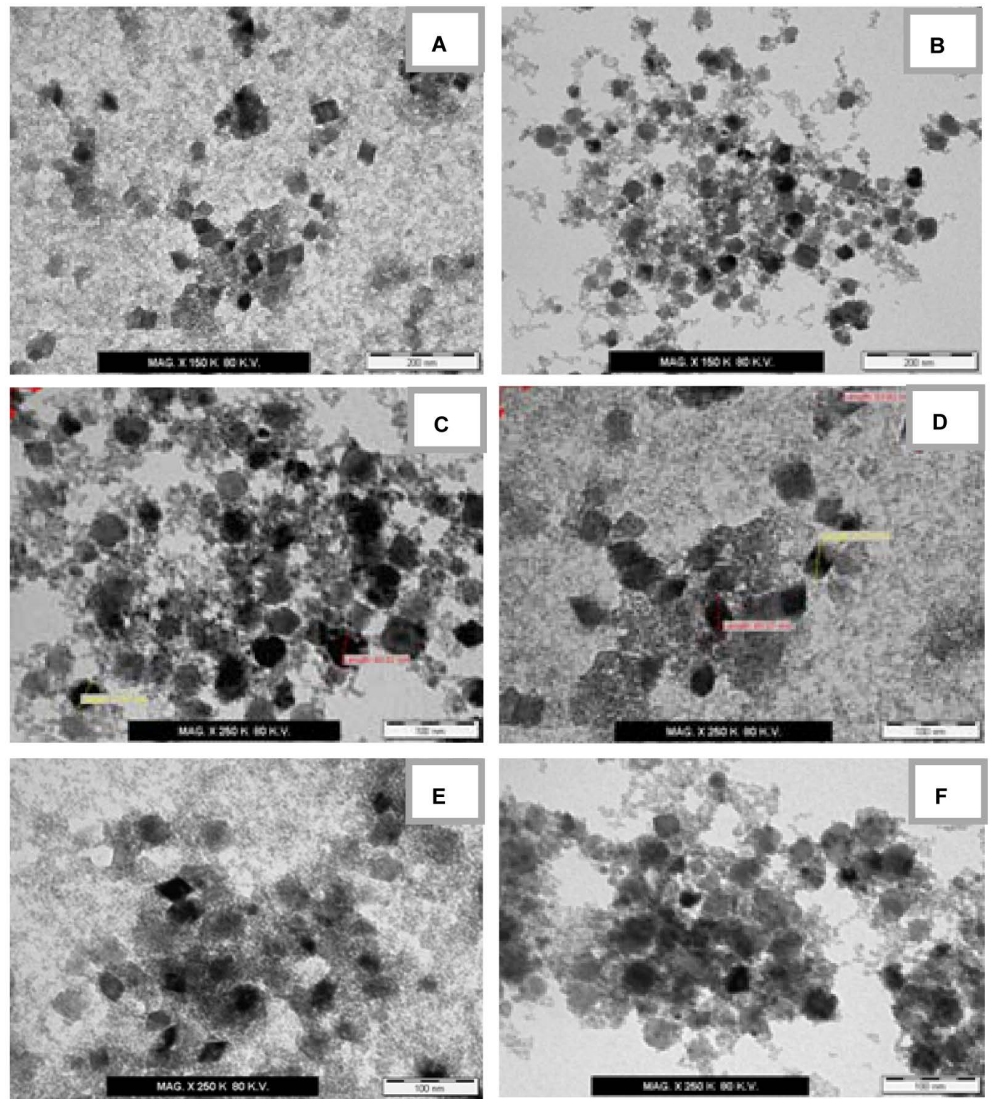

Figure 4. TEM micrographs of $\mathrm{Fe}_{2} \mathrm{O}_{3}$ (A) (C) and (E) and $\mathrm{Co}-\mathrm{Fe}_{2} \mathrm{O}_{3}$ (B) (D)and (F).

the band at $537 \mathrm{~cm}^{-1}$ shifts toward a lower frequency suggesting the possible formation of a Co-O-Fe bond. The decrease in the intensity of bands suggests the possible interaction of dopants with surface hydroxyl groups of $\mathrm{Fe}_{2} \mathrm{O}_{3}[26]$.

\subsubsection{UV-Vis Spectroscopy}

It has been believed that these narrow band gap values are beneficial for the efficient utilisation of visible light for photocatalysis. The UV-Vis spectrophotometer was used to investigate the absorption regions of $\mathrm{Fe}_{2} \mathrm{O}_{3}$ and $\mathrm{Co}-\mathrm{Fe}_{2} \mathrm{O}_{3}$, as can be seen in Figure 6. The energy band gaps (E) were calculated using the following equation [16]: 


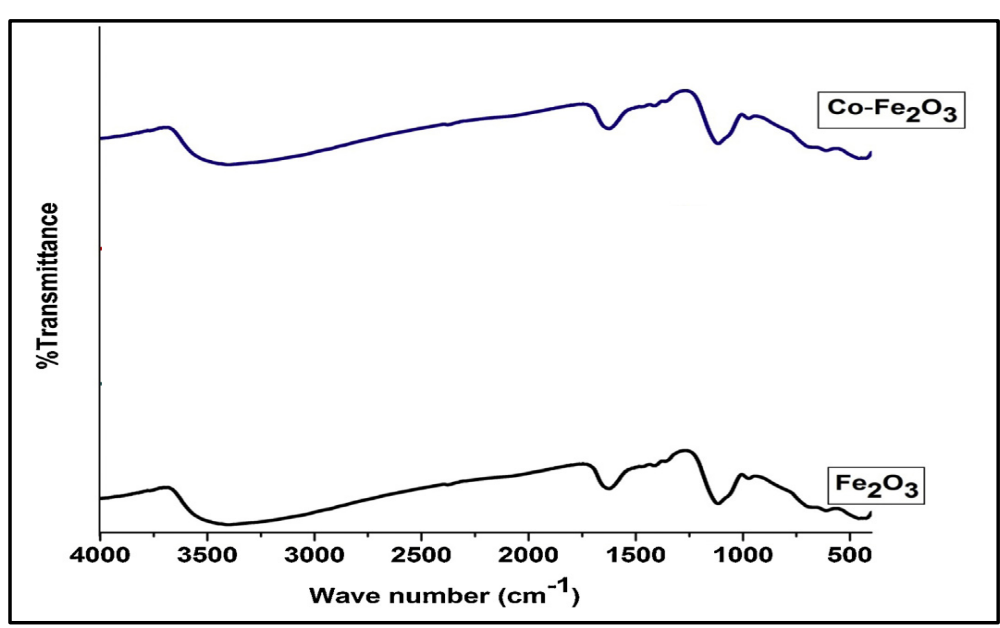

Figure 5. FT-IR spectra of $\mathrm{Fe}_{2} \mathrm{O}_{3}$ and $\mathrm{Co}-\mathrm{Fe}_{2} \mathrm{O}_{3}$.

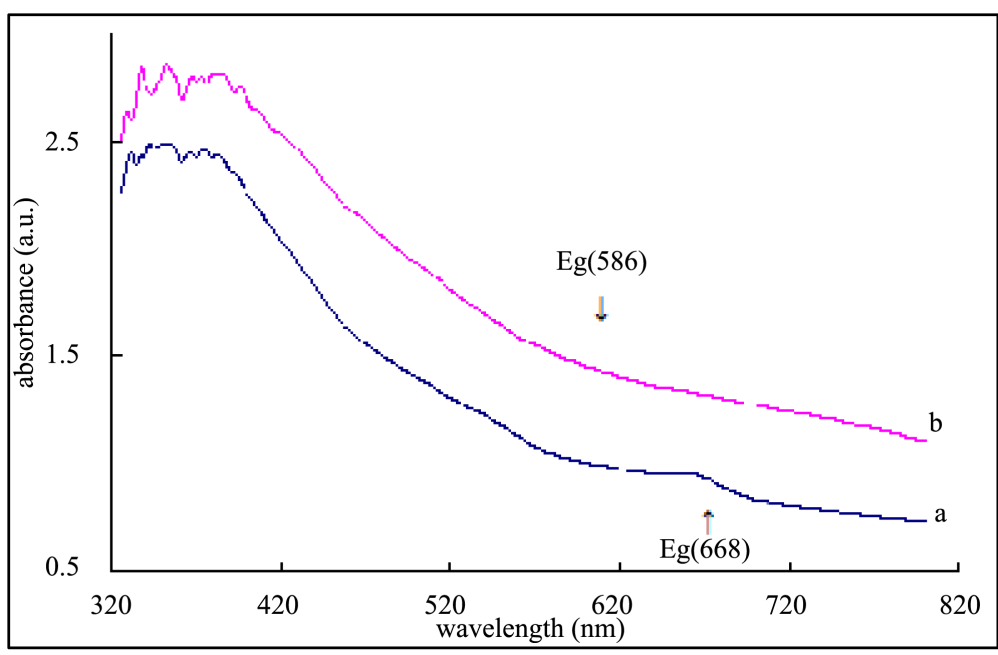

Figure 6. The UV-Vis spectra for (a) $\mathrm{Fe}_{2} \mathrm{O}_{3}$ and (b) $\mathrm{Co}-\mathrm{Fe}_{2} \mathrm{O}_{3}$.

$$
E=h \frac{C}{\lambda}
$$

As can be seen in Figure 6, there was a decrease in the spectra at the absorption edge of $\approx 668 \mathrm{~nm}$, and 586 $\mathrm{nm}$ for $\mathrm{Fe}_{2} \mathrm{O}_{3}$ and $\mathrm{Co}-\mathrm{Fe}_{2} \mathrm{O}_{3}$ respectively (indicated by an arrow) [16]. The energy band gaps were calculated to be $1.86 \mathrm{eV}$ for $\mathrm{Fe}_{2} \mathrm{O}_{3}$ and $2.01 \mathrm{eV}$ for $\mathrm{Co}-\mathrm{Fe}_{2} \mathrm{O}_{3}$. The reported values of the indirect band gap of $\mathrm{Fe}_{2} \mathrm{O}_{3}$ are in the range of 1.38 - $2.09 \mathrm{eV}$, the results are in good agreement with previous reports [27]. Moreover, it was observed that the absorption edge is extended towards the visible region for $\mathrm{Co}-\mathrm{Fe}_{2} \mathrm{O}_{3}$ compared with $\mathrm{Fe}_{2} \mathrm{O}_{3}$. This phenomenon arises due to the transfer of charge from the dopant $\left(\mathrm{Co}^{2+}\right)$ to the conduction or valence band of $\mathrm{Fe}_{2} \mathrm{O}_{3}$, which enhances visible light absorption and promotes the photocatalytic activity [27].

\section{Conclusion}

Nanocrystaline transition metal doped $\mathrm{Fe}_{2} \mathrm{O}_{3}$ powders were successfully fabricated using the microwave-hydrothermal method. The properties of the fabricated materials were investigated using different techniques, and the morphology of the fabricated nanoparticles was analysed by SEM analysis and TEM analysis. TEM images showed the $\mathrm{Co}-\mathrm{Fe}_{2} \mathrm{O}_{3}$ powders formed $36.97 \mathrm{~nm}$ crystals. Moreover, the product was characterised using an EDAX analysis that confirmed doping of iron oxide with cobalt. Work is currently in progress to use nanosized fabricated materials in this work in water purification and the removal of pollutants from wastewater. 


\section{References}

[1] Jain, T.K., Morales, M.A., Sahoo, S.K., Leslie-Pelecky, D.L. and Labhasetwar, V. (2005) Iron Oxide Nanoparticles for Sustained Delivery of Anticancer Agents. Molecular Pharmaceutics, 2, 194-205. http://dx.doi.org/10.1021/mp0500014

[2] Jordan, A., Scholz, R., Wust, P., Fähling, H. and Felix, R. (1999) Magnetic Fluid Hyperthermia (MFH): Cancer Treatment with AC Magnetic Field Induced Excitation of Biocompatible Superparamagnetic Nanoparticles. Journal of Magnetism and Magnetic Materials, 201, 413-419. http://dx.doi.org/10.1016/S0304-8853(99)00088-8

[3] Chertok, B., Moffat, B.A., David, A.E., Yu, F.Q., Bergemann, C., Ross, B.D. and Yang, V.C. (2008) Iron Oxide Nanoparticles as a Drug Delivery Vehicle for MRI Monitored Magnetic Targeting of Brain Tumors. Biomaterials, 29, 487-496. http://dx.doi.org/10.1016/j.biomaterials.2007.08.050

[4] Suresh, R., Prabu, R., Vijayaraj, A., Giribabu, K., Stephen, A. and Narayanan, V. (2012) Facile Synthesis of Cobalt Doped Hematite Nanospheres: Magnetic and Their Electrochemical Sensing Properties. Materials Chemistry and Physics, 134, 590-596. http://dx.doi.org/10.1016/j.matchemphys.2012.03.034

[5] Zboril, R., Mashlan, M. and Petridis, D. (2002) Iron (III) Oxides from Thermal Processes Synthesis, Structural and Magnetic Properties, Mössbauer Spectroscopy Characterization, and Applications. Chemistry of Materials, 14, 969-982. http://dx.doi.org/10.1021/cm0111074

[6] Chirita, M., et al. (2009) $\mathrm{Fe}_{2} \mathrm{O}_{3}$-Nanoparticles, Physical Properties and Their Photochemical and Photoelectrochemical Applications. Chemical Bulletin of Politehnica, University of Timisoara, Romania, 54, http://www.chim.upt.ro/buletin_chimie/index.htm

[7] Chen, M., et al. (2008) Preparation of Akaganeite Nanorods and Their Transformation to Sphere Shape Hematite. Journal of Nanoscience and Nanotechnology, 8, 3942-3948.

[8] Hiremath, V.A. and Venkataraman, A. (2003) Dielectric, Electrical and Infrared Studies of $\gamma-\mathrm{Fe}_{2} \mathrm{O}_{3}$ Prepared by Combustion Method. Bulletin of Materials Science, 26, 391-396. http://dx.doi.org/10.1007/BF02711182

[9] Hyeon, T., Lee, S.S., Park, J., Chung, Y., and Na, H.B. (2001) Synthesis of Highly Crystalline and Monodisperse Maghemite Nanocrystallites without a Size-Selection Process. Journal of the American Chemical Society, 123, 1279812801. http://dx.doi.org/10.1021/ja016812s

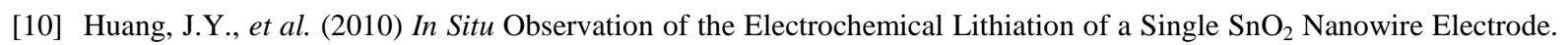
Science, 330, 1515-1520. http://dx.doi.org/10.1126/science.1195628

[11] Chakrabarti, S., Mandal, S. and Chaudhuri, S. (2005) Cobalt Doped $\gamma-\mathrm{Fe}_{2} \mathrm{O}_{3}$ Nanoparticles: Synthesis and Magnetic Properties. Nanotechnology, 16, 506-511. http://dx.doi.org/10.1088/0957-4484/16/4/029

[12] Katsuki, H. and Komarneni, S. (2011) Low Temperature Synthesis of Nano-Sized $\mathrm{BaTiO}_{3}$ Powders by the Microwave-Assisted Process. Journal of the Ceramic Society of Japan, 119, 525-527. http://dx.doi.org/10.2109/jcersj2.119.525

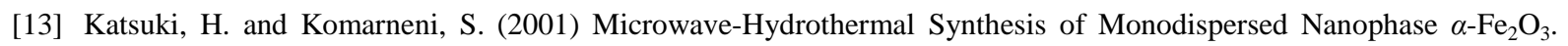
Journal of the American Ceramic Society, 84, 2313-2317. http://dx.doi.org/10.1111/j.1151-2916.2001.tb01007.x

[14] Sun, P., Wang, C., Zhou, X., Cheng, P.F., Shimanoe, K., Lu, G.Y. and Yamazoe, N. (2014) Cu-Doped $\alpha-\mathrm{Fe}_{2} \mathrm{O}_{3} \mathrm{Hie}^{-}$ rarchical Microcubes: Synthesis and Gas Sensing Properties. Sensors and Actuators B: Chemical, 193, 616-622. http://dx.doi.org/10.1016/j.snb.2013.12.015

[15] Morales, A.E., Mora, E.S. and Pal, U. (2007) Use of Diffuse Reflectance Spectroscopy for Optical Characterization of Un-Supported Nanostructures. Revista Mexicana de Fisica Supplement, 53, $18-22$.

[16] D’Souza, L.P., Shree, S. and Balakrishna, G.R. (2013) Bifunctional Titania Float for Metal Ion Reduction and Organics Degradation, via Sunlight. Industrial \& Engineering Chemistry Research, 52, 16162-16168. http://dx.doi.org/10.1021/ie402592k

[17] Pozan, G.S., Isleyen, M. and Gokcen, S. (2013) Transition Metal Coated $\mathrm{TiO}_{2}$ Nanoparticles: Synthesis, Characterization and Their Photocatalytic Activity. Applied Catalysis B: Environmental, 140, 537-545. http://dx.doi.org/10.1016/j.apcatb.2013.04.040

[18] Liu, J., Liang, C.H., Xu, G.P., Tian, Z.F., Shao, G.S. and Zhang, L.D. (2013) Ge-Doped Hematite Nanosheets with Tunable Doping Level, Structure and Improved Photoelectrochemical Performance. Nano Energy, 2, 328-336. http://dx.doi.org/10.1016/j.nanoen.2012.10.007

[19] Merkle, R.C. (2000) Molecular Building Blocks and Development Strategies for Molecular Nanotechnology. Nanotechnology, 11, 89-99. http://dx.doi.org/10.1088/0957-4484/11/2/309

[20] Habibi, M.H. and Habibi, A.H. (2013) Effect of the Thermal Treatment Conditions on the Formation of Zinc Ferrite Nanocomposite, $\mathrm{ZnFe}_{2} \mathrm{O}_{4}$, by Sol-Gel Method. Journal of Thermal Analysis and Calorimetry, 113, 843-847. http://dx.doi.org/10.1007/s10973-012-2830-4 
[21] Zhou, K.W., Wu, X.H., Wu, W.W., Xie, J., Tang, S.Q. and Liao, S. (2013) Nanocrystalline $\mathrm{LaFeO}_{3}$ Preparation and Thermal Process of Precursor. Advanced Powder Technology, 24, 359-367. http://dx.doi.org/10.1016/j.apt.2012.08.009

[22] Linxu, S. and Ping, L. (2010) Preliminary Exploration on Water Pollution from Non-Point Source in Xiang Xi River. Proceedings of the 4th International Conference on Bioinformatics and Biomedical Engineering (iCBBE), Chengdu, 18-20 June 2010, 1-5.

[23] Wu, J.-M., Zhang, T.-W., Zeng, Y.-W., Hayakawa, S., Tsuru, K. and Osaka, A. (2005) Large-Scale Preparation of Ordered Titania Nanorods with Enhanced Photocatalytic Activity. Langmuir, 21, 6995-7002. http://dx.doi.org/10.1021/la0500272

[24] Pfitzner, A., Dankesreiter, S., Eisenhofer, A. and Cherevatskaya, M. (2013) Heterogeneous Semiconductor Photocatalysis. In: König, B., Ed., Chemical Photocatalysis, de Gruyter, Berlin, 211-246. http://dx.doi.org/10.1515/9783110269246.211

[25] Pal, B. and Sharon, M. (2000) Preparation of Iron Oxide Thin Film by Metal Organic Deposition from Fe (III)-Acetylacetonate: A Study of Photocatalytic Properties. Thin Solid Films, 379, 83-88. http://dx.doi.org/10.1016/S0040-6090(00)01547-9

[26] Devi, L.G., Kottam, N., Murthy, B.N. and Kumar, S.G. (2010) Enhanced Photocatalytic Activity of Transition Metal Ions $\mathrm{Mn}^{2+}, \mathrm{Ni}^{2+}$ and $\mathrm{Zn}^{2+}$ Doped Polycrystalline Titania for the Degradation of Aniline Blue under UV/Solar Light. Journal of Molecular Catalysis A: Chemical, 328, 44-52. http://dx.doi.org/10.1016/j.molcata.2010.05.021

[27] Satheesh, R., Vignesh, K., Suganthi, A. and Rajarajan, M. (2014) Visible Light Responsive Photocatalytic Applications of Transition Metal ( $\mathrm{M}=\mathrm{Cu}, \mathrm{Ni}$ and $\mathrm{Co})$ Doped $\alpha-\mathrm{Fe}_{2} \mathrm{O}_{3}$ Nanoparticles. Journal of Environmental Chemistry Engineering, 2, 1956-1968. http://dx.doi.org/10.1016/j.jece.2014.08.016 